\title{
Visual Analysis of International Green Logistics Research in the Past Ten Years: Research Hotspots and Evolutionary Trends
}

\author{
Zhaozhao Qiao1, Peijian Wu' ${ }^{2 *}$ \\ ${ }^{1}$ School of International Trade and Economics, Anhui University of Finance \& Economics, Bengbu, China \\ ${ }^{2}$ School of Business Administration, Anhui University of Finance \& Economics, Bengbu, China \\ Email: *wupeijian@126.com
}

How to cite this paper: Qiao, Z.Z. and $\mathrm{Wu}$, P.J. (2021) Visual Analysis of International Green Logistics Research in the Past Ten Years: Research Hotspots and Evolutionary Trends. Open Access Library Journal, 8: e7559.

https://doi.org/10.4236/oalib.1107559

Received: May 21, 2021

Accepted: June 25, 2021

Published: June 28, 2021

Copyright $\odot 2021$ by author(s) and Open Access Library Inc.

This work is licensed under the Creative Commons Attribution International License (CC BY 4.0).

http://creativecommons.org/licenses/by/4.0/

\section{(c) (i) Open Access}

\begin{abstract}
In logistics-related research, green logistics is the top priority of modern circulation reform. This article describes the research hotspots and evolutionary trends of green logistics in the past ten years by analyzing relevant literature. This paper uses visual analysis tools (such as VosViewer, CiteSpace, etc.) to analyze the knowledge graph of 304 papers. This article analyzes the cooccurrence of keywords, article citations, timeline graphs, and emergent keywords. The results show that related research on green logistics has gradually penetrated management practices and technical applications. Generally speaking, these findings help describe the latest trend of green logistics, which concentrate on supply chain management, low-carbon logistics, and other hotspots.
\end{abstract}

\section{Subject Areas}

Green Logistics

\section{Keywords}

Green Logistics, Literature Measurement, Research Hotspots, Evolution Trend

\section{Introduction}

It is universally acknowledged that the logistics industry has been experiencing a swift development as economic globalization deepens across the world, however, the various emissions produced by logistics activities also impact the environ- 
ment. Early researches on green logistics include the second stage of the "New Logistics Era" proposed by Poist, which combines environmental issues with logistics at the earliest [1]; Wu calls for greater attention to environmental protection in all aspects of traditional logistics, including the recycling and utilization of waste [2]. Rodrigue et al. put forward a safe and friendly logistics system coordinated between green logistics and the environment [3]. Abbasi and Nilsson suggest that sustainable development has inspired many green and sustainable logistics activities, relieving the negative influence on goods transportation, enhancing the quality of environment, and provide the society with upbeat feedback [4]. On the other hand, Lindholm and Blinge propose that logistics activities ranging from heavy long-distance logistics to intra-city distribution, and daily road freight systems will exert a substantial external influence on the nature [5]. Ultimately, these impacts consist of traffic congestion, contamination, traffic accidents, noise, visual interference, infrastructure failures, and waste resources [6]. Moreover, these adverse external factors and the drawbacks of the logistics system itself, such as limited intelligence, personnel dependence, and vulnerability, can lead to a decline in supply chain performance at the enterprise and regional levels [7]. Chen et al. pointed out that with the rapid growth of logistics demand, the damage is also multiplying, eventually bringing irreversible effects on the economy and the entire ecosystem [8].

The above scholars have explored the specific technologies that green logistics can adopt from the perspectives of practical applications and management practices and called on everyone to pay attention to the green development of logistics. However, these studies do not explain what scholars have focus on these years and the relevant changes in research hotspots as time goes by. Therefore, this article mainly focuses on the hot content and evolution trend of green logistics research in the past ten years, revealing the specific content that scholars have concentrate on and how the research hotspot has changed with the deepening of green logistics' practice.

\section{Research Methods and Data Sources}

\subsection{Research Methods}

The VosViewer is a Java-based visualization software created in 2009 by Van Eck together with Waltman in the Netherlands, focusing on the visualization of scientific knowledge. CiteSpace is a bibliometrics tool created by Professor Chen Chaomei, a scholar. It manifests the trendy development and trend of discipline in a certain period and form several research frontier fields [9]. This paper attempts to use VosViewer and CiteSpace to classify and compare the international research results in green logistics to clarify the hot trends in the field of green logistics to provide new thoughts for the research. This article is mainly based on the theory of bibliometrics, applied mathematics and statistical methods, by calculating and analyzing the number of documents to show the development characteristics of the discipline more clearly. 


\subsection{Data Sources}

The core collection of Web of Science was selected as the retrieval source, and the advanced retrieval method was set as "title = ('GREEN LOGISTICS' or 'ENVIRONMENTAL LOGISTICS' or 'ECOLOGICAL LOGISTICS')”. Literature type: Article, language: English, the year is 2011-2020, 304 data samples were retrieved after the screening, and the retrieval time was 2021-03-24. This article selects 2011 as the initial year for screening articles, because after the Fourth World Conference on Environmental Protection (2011), universities, researchers, etc. have conducted more concrete research on domestic and foreign green logistics development, and green logistics. Research on the problems and challenges faced by logistics is gradually increasing.

\section{Basic Statistical Analysis of the Study}

\subsection{Quantity Analysis of Published Articles}

The number of papers published annually in green logistics can indicate the degree of its development over time. As can be seen from the number of documents with green logistics as the title included in the Web of Science database, from 2011 to 2020, an increasing number of papers researching green logistics appear, and the quantity of papers is maintained at about 30 each year. The number of papers with the title of Green Logistics reaches 45 in 2020. This trend indicates that international research on green logistics is more and more critical.

\subsection{Author Collaboration Network}

The author's contribution to the development of the green logistics field can be known through the visual knowledge graph analysis of the author's collaboration network. The core authors in green logistics and the cooperative relationships among the authors can be determined. The minimum number of literatures published by each author was 3, and among 709 authors, a total of 22 authors met this condition. Using VosViewer to figure out the cooperation network between authors, it can be seen that among the scholars in the field of green logistics, Agyabeng-Mensah, Afum, and Ahenkorah have carried out cooperation, and their published literature have been cited 14 times. Other authors with high citation volumes, such as Lai, were cited 265 times, and Pamucar was cited 104 times. However, there was little cooperation among these authors. It can be seen that the network density of the author's cooperation network in the field of green logistics is small, and the tightness between network nodes is low.

\subsection{Collaborative Network of Research Institutions}

The contribution of research institutions in green logistics to the development of green logistics and the cooperation among research institutions can be seen through the visualization knowledge graph analysis of the cooperation network of institutions. Meanwhile, the size of node symbolizes the total number of ar- 
ticles published by a research institution. It was found that the research institution with the most significant number of articles published was Czestochowa Tech University, which published 7 papers. Next came Hong Kong Polytech University and Linkoping University, which published 6 papers. Apart from this, the thickness and depth of colorful lines between nodes are capable of showing the collaboration year and cooperation tightness of the research institution, respectively, to form a cooperation line. The thinner lines between nodes indicate the low cooperation tightness. The node size represents the number of papers published by research institutions. Among the 398 research institutions that have made contributions to the research of green logistics, the number of institutions that have published more than 10 papers is 0 . Therefore, so far, no organization has been able to lead green logistics research. However, a lot of organizations and institutions in the Asia-Pacific region and Europe have excellent fame in studying green logistics because of the high citations, including the Hong Kong Polytechnic University (Hong Kong, 380 citations) and Wageningen University (the Netherlands, 404 citations).

\subsection{Number of Papers Published in Different Countries}

Among all the countries and regions globally, China published the most papers on green logistics research, as shown in Figure 1, 116 documents, accounting for $38 \%$ of the total published documents. Poland ranked second, with 17 papers, accounting for $6 \%$ of the whole published documents. While the United Stated ranked the third. Sweden, Brazil and the United Kingdom followed.

In terms of green logistics research, the top countries and regions are mainly developed countries and areas with developed logistics globally. The reason why China has published far more papers than other countries (regions) is closely related to the country's vigorous implementation of logistics policies and promotion of logistics education since 2009. From these articles, as one of the leading countries, the United States has reinforced its place in researching comprehensive logistics across the globe. For instance, many corporations like UPS have

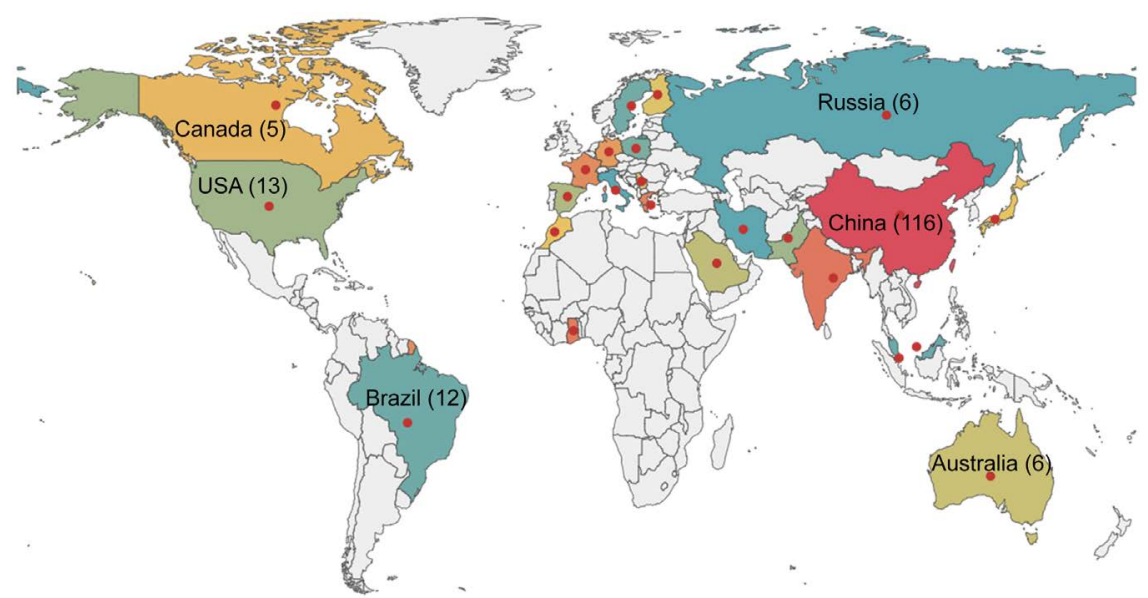

Figure 1. Country (region) distribution of literature published quantity. 
accomplished rapport in make full use of techniques to upgrade the development of green logistics through thorough research on market. Germany, Malaysia, and other countries are also relatively mature in the research of green logistics.

\section{Research Hot Spot}

The author chooses the top $20 \%$ threshold to make the ultimate map and specify keywords intermediary centricity and keywords to research the green logistic network of keywords co-occurrence.

\subsection{Keywords Co-Occurrence Analysis}

The type of analysis was set as co-occurrence, and the Unit of the study was selected as all keywords. The minimum number of co-occurrence of keywords was 5. Among 1221 keywords, 63 keywords were finally presented, as shown in Figure 2. As we all know, the theme and core point of a paper can be concluded by its frequent keywords. The size of the node manifests the centrality as is shown in the graph. As can be seen from the figure, during the period from 2011 to 2020 , of all the prominent key node, the most outstanding ones are green logistics and performance evaluation, reverse logistics and green supply chain management follow behind. It can also be seen from Figure 2 that the main focus on green logistics is green supply chain, circular economy and low-carbon logistics from most international research. There are large quantities of approaches used to optimize green logistics such as analytic hierarchy process and data envelopment analysis and so forth.

When the threshold top is $20 \%$, there are 62 keywords and 189 network connections in green logistics, and the network density is 0.0999 , indicating a low network density. The distance between keywords suggests the degree of keyword concentration. There is an inner relation between the line and keywords. Whether these keywords are closed enough is determined by the frequency of

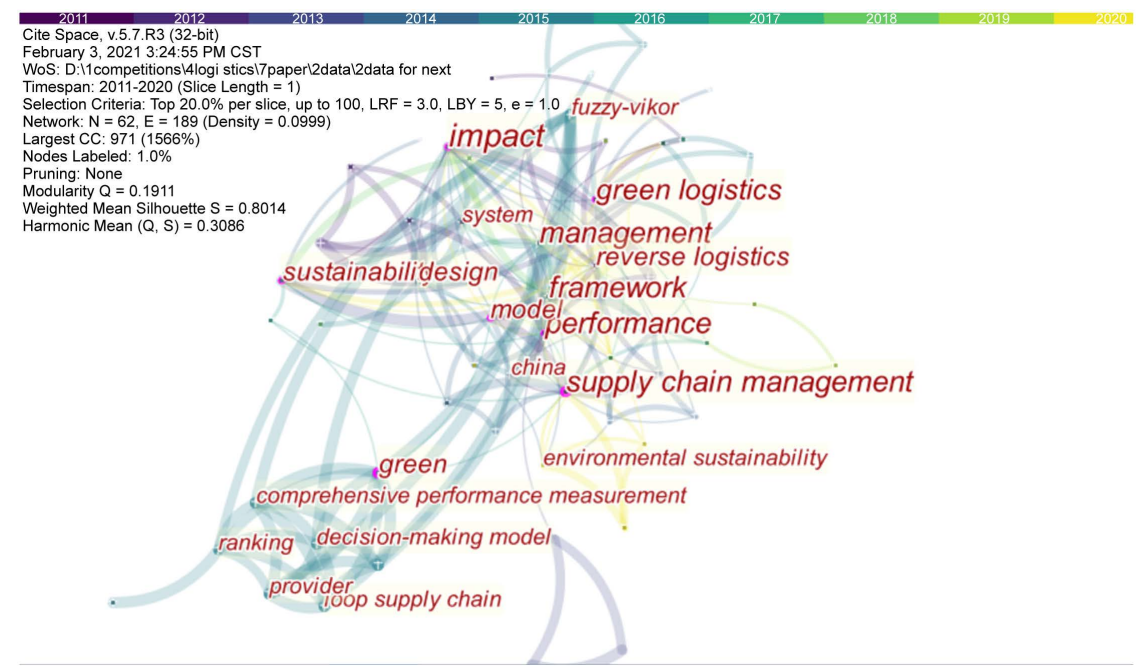

Figure 2. Keyword co-occurrence map. 
keywords occurrence. From the information of Figure 2, the keywords of highfrequency words are green logistics, green supply chain, supply chain management, strategy, empirical analysis, green, carbon dioxide emission, etc. The line between the keywords indicates the development path of the keywords, and the color of the line indicates the year in which the keywords appeared. Combined with the color depth of the lines in the figure, it is apparent that the circle layer of green logistics, model, supply chain management, system, sustainability is relatively light. What's more, empirical research, emissions, energy-economic benefits, challenges, such as keywords in layers of color is more profound, is a hit in recent years, in particular the logistics services, decision-making process, economic growth, energy consumption, such as storage, cold chain in the branch of the network knowledge atlas keywords co-occurrence end, began to appear in 2019 keywords, can be in the forefront of green logistics field of research.

\subsection{Keywords Mediation Centrality Analysis}

When the threshold is set at 20\%, 62 keywords in green logistics research in recent ten years are statistically analyzed. However, due to the space limitation, only those keywords with a frequency of 10 times or more and their mediating centrality are as follows, as shown in Table 1.

Mediation centrality refers to that in the keyword network, and a keyword exists in the path of other keywords connected. The number of existence modes shows the degree of centrality of the keyword, which manifests the significance of the keyword network in general. And it means the great mediating effect of

Table 1. Statistical table of high-frequency keywords.

\begin{tabular}{ccc}
\hline Keywords & Frequency & Centricity \\
\hline green logistics & 109 & 0.39 \\
performance & 47 & 0.32 \\
model & 41 & 0.23 \\
supply chain management & 37 & 0.46 \\
management & 34 & 0.17 \\
impact & 32 & 0.35 \\
sustainability & 31 & 0.22 \\
reverse logistics & 20 & 0.09 \\
framework & 17 & 0.2 \\
sustainable development & 12 & 0.07 \\
supply chain & 11 & 0.01 \\
environmental sustainability & 11 & 0.03 \\
system & 10 & 0.05 \\
transport & 10 & 0.01 \\
\hline
\end{tabular}


connecting other keywords [10]. In addition to green logistics, the keywords with high frequency are performance, model, supply chain management, management, impact, sustainability, etc. Supply chain management has a higher frequency and has a higher intermediary centrality. If the centrality of supply chain and transportation is 0.01 , the role of these keywords in the transmission connection in the network is weak.

\subsection{Emergent Keyword Analysis}

Emergent keywords refer to the keywords with a sudden increase in frequency in a certain period, which are used to study the dynamic development and potential problems in a particular field. They are suitable for testing the new trend and sudden changes in the development of the discipline [11]. Emergent keywords are judged according to the sudden increase in the frequency of keyword use in a certain period and have nothing to do with the frequency of keyword occurrence. For example, through sudden detection, nine abrupt keywords in green logistics from 2011 to 2020 were found, as shown in Figure 3.

As can be seen from the figure, there are different keyword bursts in each stage from 2011 to 2020. The burst of the keyword Sustainability started in 2014 and lasted until 2018, with the longest burst duration and the burst intensity of 2.45. Optimization burst lasted from 2017 to 2020, and the burst time was shorter than sustainability, but the burst intensity was 3.78 . The emergence of the industry began in 2018 and continued to 2020, with an emergence intensity of 2.91, which is a keyword with a sudden increase and a high enhancement degree in recent years. There is a significant relationship between the emergence of keywords and the research level of scholars in green logistics. When green logistics was emerging, scholars' research on green logistics tended to explore the fundamental business model of green logistics. After the green logistics business model has gradually matured, the research hotspots of green logistics have shifted from issues such as reverse logistics and carbon dioxide emissions to content such as risk control, supply chain management, and optimization programs. At the same time, the development of the logistics industry has encountered some obstacles in the new era. Therefore, green logistics has been highly

\begin{tabular}{lcccl}
$\quad$ Keywords & Year & Strength & Begin End & $2011-2020$ \\
reverse logistics & 2011 & 2.51 & 2011 & 2012 \\
environment & 2011 & 2.48 & 2012 & 2013 \\
CO2-emission & 2011 & 3.85 & 2013 & 2014 \\
sustainability & 2011 & 2.45 & 2014 & 2018 \\
performance & 2011 & 3.85 & 2016 & 2018 \\
model & 2011 & 2.99 & 2016 & 2017 \\
optimization & 2011 & 3.78 & 2017 & 2020 \\
supply chain management & 2011 & 3.5 & 2017 & 2018 \\
\hline industry & 2011 & 2.91 & 2018 & 2020
\end{tabular}

Figure 3. Emergent detection of green logistics keywords. 
praised by scholars from international research institutions. In particular, the research on green logistics supply chain and optimization schemes has always received extensive and lasting attention from the academic community.

\section{Research Trend Analysis}

\subsection{Analysis of Co-Cited References}

Based on the literature co-citation map, the most influential publications in green logistics in recent ten years were analyzed, and the co-citation network was constructed. In VosViewer, the minimum number of citations is set to 30 items to build the co-cited visual network graph, as shown in Figure 4, we can see that the circular nodes in the figure represent the name of the first author in the selected article and the publication year of the paper. These phenomena will further promote the subsequent research on the influence of the literature. The color of the node and the link indicate the time of publication and the time when the two documents were jointly cited, respectively. The charts in the literature show the characteristics of "partial concentration and overall dispersion," which indicates that some green logistics research has been widely recognized. Some ideas and conclusions worthy of reference have been generated. Many papers with high citation volume appeared in 2012, which was a year of great significance for the study of green logistics. The figure lists the documents with the highest citation frequency, including publication year, paper title, citation frequency, paper topic, etc. The most cited research is the paper of Dekker et al., which studied the earliest methodology of the connection between operational research knowledge and the field of green logistics, with the most considerable citation amount (401 times) and 22 connection points [12]. According to this case study paper related to green logistics published by Ubeda et al., there are 16 connection points with other papers, and it has been cited up to 171 times so far. In general, this paper has a high impact [13]. The literature of the above scholars has a wide and profound influence in the research field of green logistics. These literatures have been cited many times, expounding the research methods and suitable cases of green logistics from different angles.

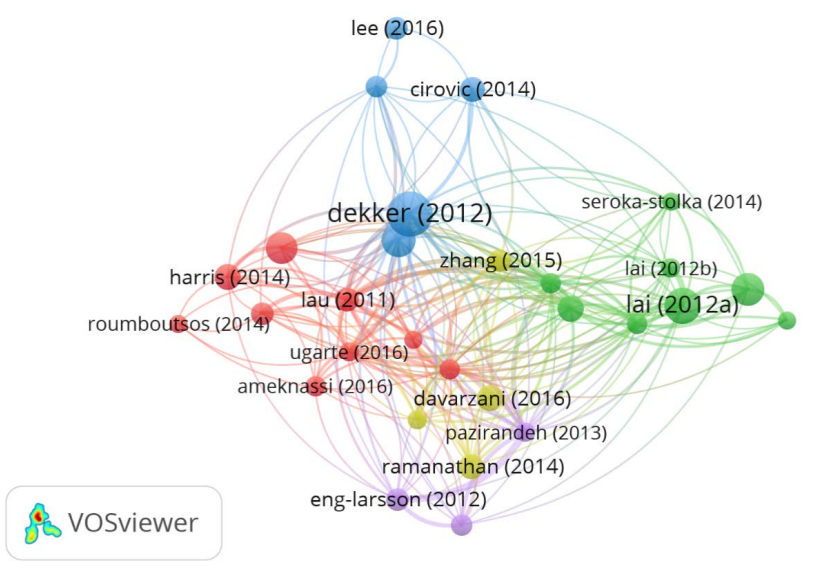

Figure 4. Analysis of citation volume of literature. 
In the current research stage, the related research of green logistics mainly focuses on the development background and theoretical basis of this theme. In addition, current research also pays attention to the problems of the development of green logistics. Many scholars have also made strategies and practical application models that contribute to the development of green logistics. The research on these problems is still in the theoretical stage. The specific implementation mode and operation method has not been unified and understood. The international research on green logistics focuses on managing green logistics and the specific activities of developing green logistics.

As an extremely important branch of macro-supply chain management, logistics management involves real-time scheduling schemes in a dynamic environment, including logistics schemes that coordinate thousands of packaged goods and container goods, and is very important for the research of green logistics. Green logistics is defined as planning, controlling, managing, and implementing logistics systems through advanced logistics technology and environmental management, aiming at reducing pollutant emissions and improving logistics efficiency [14] [15] [16]. G \& SL focuses not only on providing green products or services to customers but also on the life cycle of green and sustainable logistics processes [17] [18]. Various green logistics modes, activities, and people proposed and gradually realized behaviors from government regulations to technological innovations. For example, the construction of green logistics network, reverse logistics, emission control, electric freight vehicles, mode switching, and multimodal transport, energy efficiency, collaboration, outsourcing, and all the like [19]-[26]. The subjects related to G \& SL have achieved considerable academic achievements and practical performance. But in general, the research on green logistics is still at the basic stage, and the current research content is still unable to cope with the complex cooperation within the logistics industry and the uncertain challenges brought by the external market.

\subsection{Time Axis Cluster Diagram Analysis}

The time axis diagram outlines the relationship between clusters and the historical span of the literature in a cluster. Each cluster is arranged in chronological order, and different clusters correspond to other themes. The time direction among clusters can be seen from the depth of time color, and the development trend of different research topics can be obtained. Take the threshold value top = $20 \%$ to draw the clustering diagram of the time axis of keywords in the field of green logistics, as shown in Figure 5 . The node line in the figure is 3609 , and the average contour value $S=0.9071$, indicating that the clustering effect of green logistics keywords is noticeable.

Keywords by Figure 5 show that green logistics cluster is divided into 18 categories, respectively by the vehicle routing, logistics companies, green economy, carbon dioxide emissions, cost optimization, just in time, discrete event simulation, logistics performance index, fuzzy set theory, logistics, case studies, multi-objective optimization, resource advantage, logistics system, green, green pratice, sustainable 


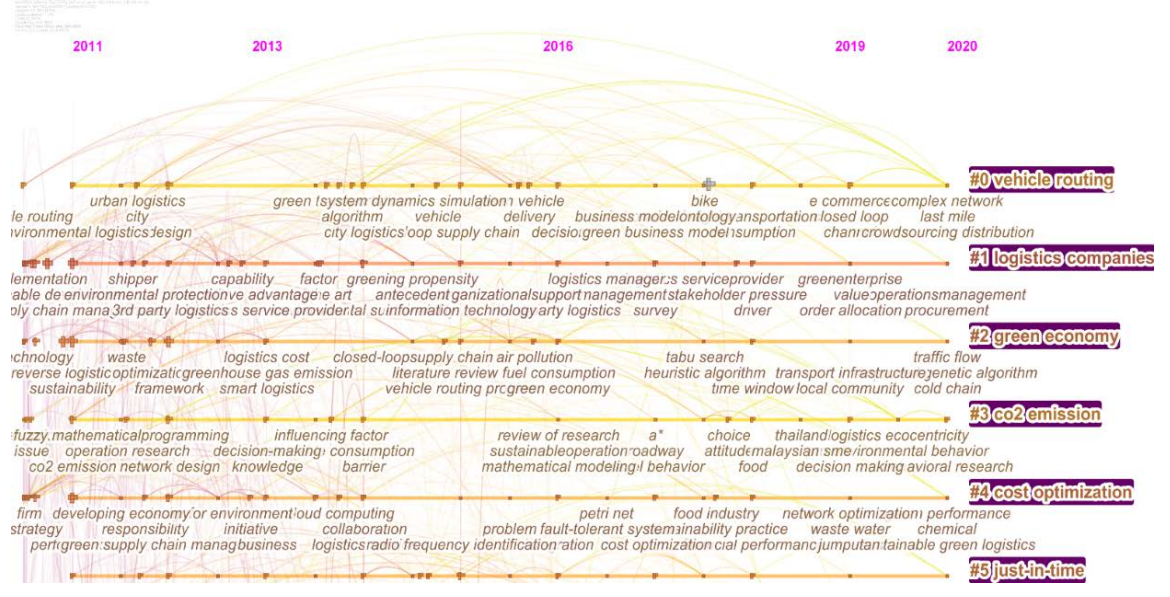

Figure 5. Timeline map of keywords in green logistics field.

supply chain, Closed-loop supply chain naming. Each cluster roughly presents an evolution trend of the tip at both ends and width in the middle. It can be seen that the transition time is 2017. Research on the green logistics field from 2011 to 2013 is relatively scattered, while research on the green logistics field from 2014 to 2017 is relatively concentrated. The line of each cluster in the figure represents the tightness of the keywords in the cluster. For example, the line of cluster \# 0 is thick, indicating a high tightness of this type of keyword.

From the time axis of each cluster in the figure, we can know the changing trend of each cluster keyword. Clustering \# 0 , for example, in the industry, system, competitive enterprise, innovation and design sustainable, green transportation, logistics, and other keywords appeared in the 2017 years ago, the level of the cooperation gravity model, vertical gravity model, cooperation, logistics, logistics services, service providers and other keywords appeared in the 2017 years later, the sustainable logistics nodes is more extensive, research in the field of green logistics has begun to develop more effective logistics activities guided by the concept of sustainable logistics. Keywords such as logistics manager, method research, third-party logistics, and the smart city gradually appeared from 2016 to 2020, indicating that research in green logistics focuses more on practical application. Focus on the benefits that specific approaches can provide to cities, businesses, etc. Clustering implementation in \# 2, green logistics, competitive advantage, low carbon, etc. in 2014, before the keyword appears since 2017 monetary expansion, cost management, method, tools, order allocation, management practices, the channel behavior research, decision-making, and so on keywords, show that green logistics research focuses on the efficient cost management in the practice.

\subsection{The Stage Development Rule and Trend of Green Logistics}

1) The first stage: the embryonic stage of green logistics

The report called "Our Common Future" introduced that to achieve long-term and sustainable development, various measures must be taken to protect envi- 
ronment [27]. Since 1999, the number of papers related to green logistics has gradually increased, and the international green logistics has explored more theories, policies, and management, such as environmental management, supply chain management, and green logistics. At this time, the international green logistics research focuses on considering green from the perspective of the whole supply chain. Murphy et al. pointed out that environmental issues affect many logistics decisions in the entire value chain. In Western industrialized countries, green logistics decisions of recycling materials, reducing consumption, and re-using materials are prevalent.

2) The second stage: the development stage of green logistics

From 2007 to 2014, international research on green logistics began to focus on solving practical problems such as models, algorithms, optimization, sustainability, carbon emissions, reverse logistics, and the application of technologies in the green logistics activities. Scholars' research focused on the technologies used in each link of the logistics process. For example, Subramanian et al.'s study borrowed innovation diffusion theory and data from SMEs to develop and test a conceptual model to empirically study the green and cost-effectiveness between cloud service providers and SMEs in China.

3) The third stage: the adjustment stage of green logistics

From 2015 to 2020, the number and frequency of keywords decreased, and the hot words such as cost management, green logistics management practices, channel behavior research, decision making, error tolerance system, cost optimization, green logistics activities, green practices also gradually emerged. According to the analysis of the existing literature and the mutation words, it can be seen that the research of supply chain management is a continuous hot topic. For example, Trivellas et al. explored the relationship between green supply chain management practices and three different performances, namely supply chain, green (environment), and business performance, and control environmental vitality in their study. Achieving sustainable performance requires logistics managers to leverage all available resources and expertise.

\section{Conclusions and Prospect}

\subsection{Conclusions}

In this paper, by using literature metrological analysis software VosViewer and CiteSpace reviewed include green logistics for the title of 304 over the past 10 years, a valuable paper to scholars' literature cited amount and annual release quantity, make visual analysis and so on research keywords, to help to understand the status of the global green logistics overall research and academic progress. And the evolution track of research hotspots are summarized and shown, and the following conclusions are drawn:

1) Through a cooperative network analysis in the field of green logistics core authors and core institutions, determine the internal relations of cooperation network, it is found that the cooperation between the author, rarely close team 
has not been formed among scholars, and the collaboration between research institutions also is more petite, future research should strengthen the research institutions for the construction of the green logistics research and deepen cooperation.

2) Through the analysis of keyword co-occurrence and keyword intermediary centrality, it is found that supply chain management, carbon dioxide emission, service provider, green supply chain, etc. Furthermore, through the detection and analysis of emergent words, it is found that emergent keywords in the field of green logistics in different periods have gone through an evolution process, from the perspective of reverse logistics and carbon emission refinement to the focus of optimization and supply chain management.

3) Through the time axis cluster diagram analysis of green logistics keywords, it is found that green practice and supply chain management are the research frontier points. International scholars' researches on green logistics from 2011 to 2020 follows from the basic concept, connotation, theory, model algorithm innovation, cost management, and then deepen to the practice of green logistics management. Research on co-cited literature shows that some literatures with a high citation amount, have had a significant impact on the combined research of green logistics and other disciplines. The knowledge dissemination speed of green logistics is getting faster and faster.

\subsection{Prospect}

In terms of the extraction of English literature, this paper still has some shortcomings. For example, the extraction of co-cited literature is not comprehensive enough. On the other hand, the number of foreign literatures collected is not too large, so that a few hot topics may be omitted. In the future, further research on co-citation of Web of Science literature needs to be done, and the selection of foreign literature and the construction of search terms also need to be more accurate to ensure the comprehensiveness of the analysis.

Future research on green logistics can be divided into three directions. First, strengthen the cooperation between global scholars and research institutions to explore and improve the comprehensive evaluation framework of green logistics performance. Second, future research can focus on sustainable development goals, green logistics practices, supply chain management; the third is to study the logistics practice and management performance of green logistics projects and enterprises and promote green logistics in the actual operation of enterprises.

\section{Conflicts of Interest}

The authors declare no conflicts of interest regarding the publication of this paper.

\section{References}

[1] Poist, R. (1989) Evolution of Conceptual Approaches to the Design of Logistics Systems: A Sequel. Transportation Journal, 28, 35-39. 
[2] Wu, H. and Dunn, S.C. (1995) Environmentally Responsible Logistics Systems. International Journal of Physical Distribution \& Logistics Management, 25, 20-38. https://doi.org/10.1108/09600039510083925

[3] Rodrigue, J.-P., Slack, B. and Comtois, C. (2017) Green Logistics. In: Brewer, A.M., Button, K.J. and Hensher, D.A., Eds., Handbook of Logistics and Supply-Chain Management, Vol. 2, Emerald Group Publishing Limited, Bingley, 339-350. https://doi.org/10.1108/9780080435930-021

[4] Maisam, A. and Fredrik, N. (2016) Developing Environmentally Sustainable Logistics. Exploring Themes and Challenges from a Logistics Service Providers' Perspective. Transportation Research Part D: Transport \& Environment, 46, 273-283. https://doi.org/10.1016/j.trd.2016.04.004

[5] Lindholm, M.E. and Blinge, M. (2014) Assessing Knowledge and Awareness of the Sustainable Urban Freight Transport among Swedish Local Authority Policy Planners. Transport Policy, 32, 124-131. https://doi.org/10.1016/j.tranpol.2014.01.004

[6] Puri, B.N. (2017) Sustainable Transport and Inter Modal Mix. Transport and Communications Bulletin for Asia and the Pacific, No. 87, 54-66.

[7] Srivastava, S.K. (2007) Green Supply-Chain Management: A State-of-the-Art Literature Review. International Journal of Management Reviews, 9, 53-80. https://doi.org/10.1111/j.1468-2370.2007.00202.x

[8] Chen, Z., Dong, J. and Ren, R. (2017) Urban Underground Logistics System in China: Opportunities or Challenges? Underground Space, 2, 195-208. https://doi.org/10.1016/j.undsp.2017.08.002

[9] Chen, C. and Song, M. (2019) Visualizing a Field of Research: A Methodology of Systematic Scientometric Reviews. PLoS ONE, 14, e0223994. https://doi.org/10.1371/journal.pone.0223994

[10] Liu, H., Jiang, Y., Fan, H., Wang, X. and Zhao, K. (2021) Visualization Analysis of Knowledge Network Research Based on Mapping Knowledge. Journal of Signal Processing Systems, 93, 333-344. https://doi.org/10.1007/s11265-020-01595-2

[11] Chen, C.M. (2009) Cite Space: Recognition and Visualization of New Trends and New Developments in Scientific Literature. Journal of Information, 8, 401-421.

[12] Dekker, R., Bloemhof, J. and Mallidis, I. (2012) Operations Research for Green Logistics-An Overview of Aspects, Issues, Contributions and Challenges. European Journal of Operational Research, 219, 671-679.

https://doi.org/10.1016/j.ejor.2011.11.010

[13] Ubeda, S., Arcelus, F.J. and Faulin, J. (2011) Green Logistics at Eroski: A Case Study. International Journal of Production Economics, 131, 44-51.

https://doi.org/10.1016/j.ijpe.2010.04.041

[14] Cosimato, S. and Troisi, O. (2015) Green Supply Chain Management. TQM Journal, 27, 256-276. https://doi.org/10.1108/TQM-01-2015-0007

[15] Lee, P., Kwon, O. and Ruan, X. (2019) Sustainability Challenges in Maritime Transport and Logistics Industry and Its Way Ahead. Sustainability, 11, Article No. 1331. https://doi.org/10.3390/su11051331

[16] Bask, A. and Rajahonka, M. (2017) The Role of Environmental Sustainability in the Freight Transport Mode Choice: A Systematic Literature Review with Focus on the EU. International Journal of Physical Distribution and Logistics Management, 47, 560-602. https://doi.org/10.1108/IJPDLM-03-2017-0127

[17] Pourhejazy, P., Sarkis, J. and Zhu, Q. (2019) A Fuzzy-Based Decision Aid Method for Product Deletion of Fast Moving Consumer Goods. Expert Systems with Applications, 119, 272-288. https://doi.org/10.1016/j.eswa.2018.11.001 
[18] Zhang, S., Lee, C.K.M., Chan, H.K., Choy, K.L. and Wu, Z. (2015) Swarm Intelligence Applied in Green Logistics: A Literature Review. Engineering Applications of Artificial Intelligence, 37, 154-169. https://doi.org/10.1016/j.engappai.2014.09.007

[19] Pourya, P., Kwon, O.K. and Lim, H. (2019) Integrating Sustainability into the Optimization of Fuel Logistics Networks. KSCE Journal of Civil Engineering, 23, 1369-1383. https://doi.org/10.1007/s12205-019-1373-7

[20] Ramos, T.R.P., Gomes, M.I. and Barbosa-Póvoa, A.P. (2014) Planning a Sustainable Reverse Logistics System: Balancing Costs with Environmental and Social Concerns. Omega, 48, 60-74. https://doi.org/10.1016/j.omega.2013.11.006

[21] Mattila, T. and Antikainen, R. (2011) Backcasting Sustainable Freight Transport Systems for Europe in 2050. Energy Policy, 39, 1241-1248.

https://doi.org/10.1016/j.enpol.2010.11.051

[22] Ahani, P., Arantes, A. and Melo, S. (2016) A Portfolio Approach for Optimal Fleet Replacement toward Sustainable Urban Freight Transportation. Transportation Research Part D: Transport and Environment, 48, 357-368.

https://doi.org/10.1016/j.trd.2016.08.019

[23] Kelle, P., Song, J., Jin, M., Schneider, H. and Claypool, C. (2019) Evaluation of Operational and Environmental Sustainability Tradeoffs in Multimodal Freight Transportation Planning. International Journal of Production Economics, 209, 411-420. https://doi.org/10.1016/j.ijpe.2018.08.011

[24] Marchi, B. and Zanoni, S. (2017) Supply Chain Management for Improved Energy Efficiency: Review and Opportunities. Energies, 10, Article No. 1618. https://doi.org/10.3390/en10101618

[25] Ramanathan, U., Bentley, Y. and Pang, G. (2014) The Role of Collaboration in the UK Green Supply Chains: An Exploratory Study of the Perspectives of Suppliers, Logistics and Retailers. Journal of Cleaner Production, 70, 231-241. https://doi.org/10.1016/j.jclepro.2014.02.026

[26] Agrawal, S., Singh, R.K. and Murtaza, Q. (2016) Outsourcing Decisions in Reverse Logistics: Sustainable Balanced Scorecard and Graph Theoretic Approach. Resources, Conservation and Recycling, 108, 41-53. https://doi.org/10.1016/j.resconrec.2016.01.004

[27] World Commission on Environment and Development. (1987) Our Common Future. United Nations, New York. 